\title{
DIFFERENCES IN AEROSOL OPTICAL PROPERTIES AND CORRESPONDING RADIATIVE EFFECTS OF HAZE EVENTS BETWEEN SUMMER AND WINTER IN A MEGA-CITY OF CENTRAL CHINA
}

\author{
Shikuan Jin ${ }^{1}$, Yingying Ma ${ }^{1,2, *}$, Yinbao Jin ${ }^{1}$, Yuting Guan ${ }^{1}$, Ming Zhang ${ }^{3}$ \\ ${ }^{1}$ State Key Laboratory of Information Engineering in Surveying, Mapping and Remote Sensing, Wuhan University, Wuhan, Hubei \\ Province 430079, China \\ ${ }^{2}$ Collaborative Innovation Center for Geospatial Technology, Wuhan 430079, China \\ ${ }^{3}$ Department of Geography, School of Earth Sciences, China University of Geosciences, Wuhan 430074, China
}

\begin{abstract}
Commission III, WG III/8
KEY WORDS: Aerosols, Radiative effect, Haze, Shortwave
\end{abstract}

\begin{abstract}
:
Aerosol optical properties and corresponding radiative effect (ARE) in ultraviolet (UV), visible (VIS), near-infrared (NIR), and shortwave (SW) during haze periods between winter and summer of Wuhan were compared. With the development of haze, the average aerosol optical depth (AOD) increased from 0.34 to 0.79 in winter and from 0.64 to 1.36 in summer. The aerosol volume size distribution (ASD) showed that obvious increases in fine mode particles in both winter and summer with haze occurring. The single scattering albedo (SSA) increased significantly in both seasons as a result of the emergence of numerous non-absorbent aerosols when haze occurred. The ARE at UV, VIS, NIR, and SW changed in winter (summer) from $-8.29 \mathrm{~W} / \mathrm{m}^{2}$ to $-10.88 \mathrm{~W} / \mathrm{m}^{2}(-$ $8.32 \mathrm{~W} / \mathrm{m}^{2}$ to $\left.-11.06 \mathrm{~W} / \mathrm{m}^{2}\right)$, from $-43.26 \mathrm{~W} / \mathrm{m}^{2}$ to $-66.04 \mathrm{~W} / \mathrm{m}^{2}\left(56.33 \mathrm{~W} / \mathrm{m}^{2}\right.$ to $\left.-76.94 \mathrm{~W} / \mathrm{m}^{2}\right)$, from $-21.90 \mathrm{~W} / \mathrm{m}^{2}$ to $-44.57 \mathrm{~W} / \mathrm{m}^{2}(-$ $31.36 \mathrm{~W} / \mathrm{m}^{2}$ to $\left.-48.67 \mathrm{~W} / \mathrm{m}^{2}\right)$, and from $-73.46 \mathrm{~W} / \mathrm{m}^{2}$ to $-119.49 \mathrm{~W} / \mathrm{m}^{2}\left(-8.32 \mathrm{~W} / \mathrm{m}^{2}\right.$ to $\left.-11.06 \mathrm{~W} / \mathrm{m}^{2}\right)$ respectively, when air conditions changed from clear to hazy. The variations in ARE fraction of UV, VIS, and NIR in SW depended much more on particle size rather than SSA. The ARE fraction of UV and VIS decreased while it of NIR increased in SW, when haze developed. Back trajectory analysis with active fire areas from Moderate Resolution Imaging Spectroradiometer (MODIS) indicated that the BC originated from the North in summer, while active fires in winter were rare.
\end{abstract}

\section{INTRODUCTION}

Aerosols have significant effects on climate change, radiation balance, and hydrological cycle (Ramanathan et al., 2001). It influences on the earth's radiation budget balance, not only directly by scattering and absorbing incoming solar radiation, but also indirectly by modifying the microphysical properties of clouds (Albrecht, 1989; Hansen et al., 1997; Haywood and Boucher, 2000). In recent years, increase in anthropogenic aerosol from developing countries owing to rapid industrial and economic development has been proved, and triggered widespread haze events in China (Huang et al., 2014; Tao et al., 2016). The fifth assessment report of the intergovernmental panel on climate change indicated that the increase in anthropogenic aerosol has enhanced aerosol radiative effects (AREs) producing a strong cooling effect on the ground, which can partially offset the greenhouse effect (Stocker et al., 2013). Except for the influence on climate change and hydrological cycle, aerosols also play an important role in air pollution environmental problems.

Wuhan is a mega-city in Central China, located in the eastern portion of the Jianghan plain and the Yangtze River middle reaches. Large amounts of water vapor originating from rivers and lakes make the city under relatively high humidity conditions. In recent year, it has been suffering from air pollution problems due to an increase in anthropogenic aerosol emissions caused by rapid economic and industrial development. The formation of haze was largely driven by changes in meteorological conditions (Guo et al., 2014). In winter, because of climatic conditions that are beneficial to the accumulation of pollutant particles, large-scale regional haze events generally occur relatively frequently (Yaoqing et al., 2007; Yele Sun et al., 2006). In summer, by contrast, haze occur because of pollutant aerosols from biomass burning from both local and remote transmission (Zhang et al., 2014), usually last for a relatively short period of time. Some studies have investigated that the chemical composition of aerosols based on sampling near the ground during haze periods in Wuhan (Lyu et al., 2016; Lyu et al., 2015). While, the AREs in each sub-band are related to the compositions, particle sizes, and absorbing and scattering capacities of aerosols, which can change dramatically during haze periods and require thorough investigation as well.
In this study, we conducted a full investigation to aerosol optical properties and their AREs in ultraviolet (UV), visible (VIS), nearinfrared (NIR), and shortwave (SW) during haze periods over Wuhan and compared their differences between summer and winter. We selected two haze events, one each from the winter and summer of 2014, which is the most recent year in which haze events occurred in both summer and winter. The winter event lasted from January 12 to 24 , 2014, and the summer event lasted from July 21 to 30, 2014. In addition, the Hybrid Single-Particle Lagrangian Integrated Trajectory (HYSPLIT) model and the Moderate-resolution Imaging Spectroradiometer (MODIS) active fire products were used to understand the influences of surrounding biomass combustion during haze periods.

\section{MEASUREMENTS AND METHODS}

\subsection{Data and instrument}

The observation data was acquired from a Cimel sun-sky radiometer (CE-318) installed on the roof of the State Key Laboratory of Information Engineering in Surveying, Mapping, and Remote Sensing $\left(114^{\circ} 21^{\prime} \mathrm{E}, 30^{\circ} 32^{\prime} \mathrm{N}\right)$ at Wuhan University, Wuhan. The instrument has an approximately $1.2^{\circ}$ full angle field of view and two detectors, observing direct solar, aureole, and sky radiance automatically in eight spectral channels: 340 , 380, 440, 500, 675, 870, 940, and $1020 \mathrm{~nm}$ (Holben et al., 1998). It is calibrated annually from the China Meteorological Administration Aerosol Remote Sensing Network (Che et al., 2009).

The active fire data was from Moderate Resolution Imaging Spectroradiometer (MODIS) global fire area products. The humidity data used in this study were obtained from the NOAA's National Climatic Data Center (NCDC), while PM2.5 (particulate matter with aerodynamic diameter less than 2.5 micrometers) and PM10 (particulate matter with aerodynamic diameter less than 10 micrometers) data were acquired from the 
China National Environmental Monitoring Center (CNEMC). According to the environmental air quality index (AQI) technical requirements (HJ 633-2012), haze days are defined as those on which the daily average mass concentration of PM2.5 was above $75 \mu \mathrm{g} / \mathrm{m}^{3}$. Details of haze days are shown in Table 1.

\begin{tabular}{lll}
\multicolumn{3}{c}{ Table. 1 Days with clear air conditions and haze periods in 2014 in Wuhan } \\
\hline & January & July \\
\hline Clear air & $12-22$ & $21-26,29-30$ \\
Haze & $12-20,23-24$ & $27-28$ \\
\hline
\end{tabular}

\subsection{Methods}

2.2.1 Inversion of aerosol optical properties: The aerosol optical properties were retrieved from the measurements of the Cimel sun-sky radiometer at 340, 380, 440, 500, 675, 870, and $1020 \mathrm{~nm}$, based on the method of Dubovik and King (2000). The Ångström exponent (AE) proposed by Ångström (1929) was computed from the negative of the first derivative of AOD with the associated wavelength on a logarithmic scale (Eck et al., 1999). The volume size distribution (ASD), asymmetry factor (ASY), and single-scattering albedo (SSA) was were retrieved from the direct sun observations and sky irradiance with the uncertainty less than $5 \%$ at $440,675,870$, and 1020 nm (Dubovik et al., 2002; Dubovik and King, 2000). The uncertainty of SSA inversion was controlled between 0.03 and 0.07 , depending on the aerosol loading and types (Dubovik et al., 2000).

2.2.2 Aerosol radiative effects calculation: The ARE was the difference between the net radiative flux with and without aerosols in each spectral interval. It was calculated using the libRadtran model (Mayer and Kylling, 2005) with input parameters of aerosol optical properties, precipitable water vapor acquired from the band of sun-sky radiometer at $940 \mathrm{~nm}$, and total ozone column from the Ozone Monitoring Instrument (OMI) onboard the Aura spacecraft, and surface albedo were input into the model as parameters for irradiance simulation (Moody et al., 2005), in each sub-band: UV (280$400 \mathrm{~nm})$, VIS (400-700nm), VIS (700-2800nm), and SW (280$2800 \mathrm{~nm})$ spectra. In order to maintain consistency between the two seasons, the solar zenith angle was limited to $60^{\circ} \pm 5^{\circ}$, because this angle strongly influences the ARE evaluation (Haywood and Boucher, 2000)

2.2.3 Backward trajectories simulation: The Hybrid Single-Particle Lagrangian Integrated Trajectory (HYSPLIT) model was developed by the National Oceanic and Atmospheric Administration (NOAA) Air Resource Laboratory (Draxier and Hess, 1998). It is a complete air trajectory model that is widely used for calculating simple air parcel trajectories, complex transport, dispersion, chemical transformation, and deposition simulations (Stein et al., 2015). Meteorological files as input data for running the HYSPLIT model were acquired from reanalysis data of the NOAA. In this study, the HYSPLIT model was used in combination with active fire data from MODIS global fire area products to analyse the influence of the surrounding regions on Wuhan during the haze periods.

\section{RESULTS}

\subsection{Investigation of aerosol optical properties}

3.1.1 Aerosol optical depth and Ångström exponent: The variations of $\mathrm{AOD}$ and $\mathrm{AE}$ during the study periods is shown in
Fig. 1. Data from July 24-25 are missing due to adverse weather factors. In winter, the daily mean AOD was 0.34 under clear air and was 0.79 in haze event. It fluctuated drastically from maximum 1.55 (January 13) to minimum 0.29 (January 21) during whole study periods and the AE changed from 0.84 to 1.74. Before January 20, the mean AOD was 0.94 showing relatively heavy haze. After this, AOD decreased and reached about 0.37 showing the influence on coarse mode particles. While, the daily mean AOD changed from 0.64 under clear air to 1.36 during haze event in summer. The mean daily $\mathrm{AE}$ almost unchanged around 1.40 showing dominant fine mode particle. In general, compared with the haze in winter, the mean $\mathrm{AOD}$ and $\mathrm{AE}$ were both larger during summer haze periods.
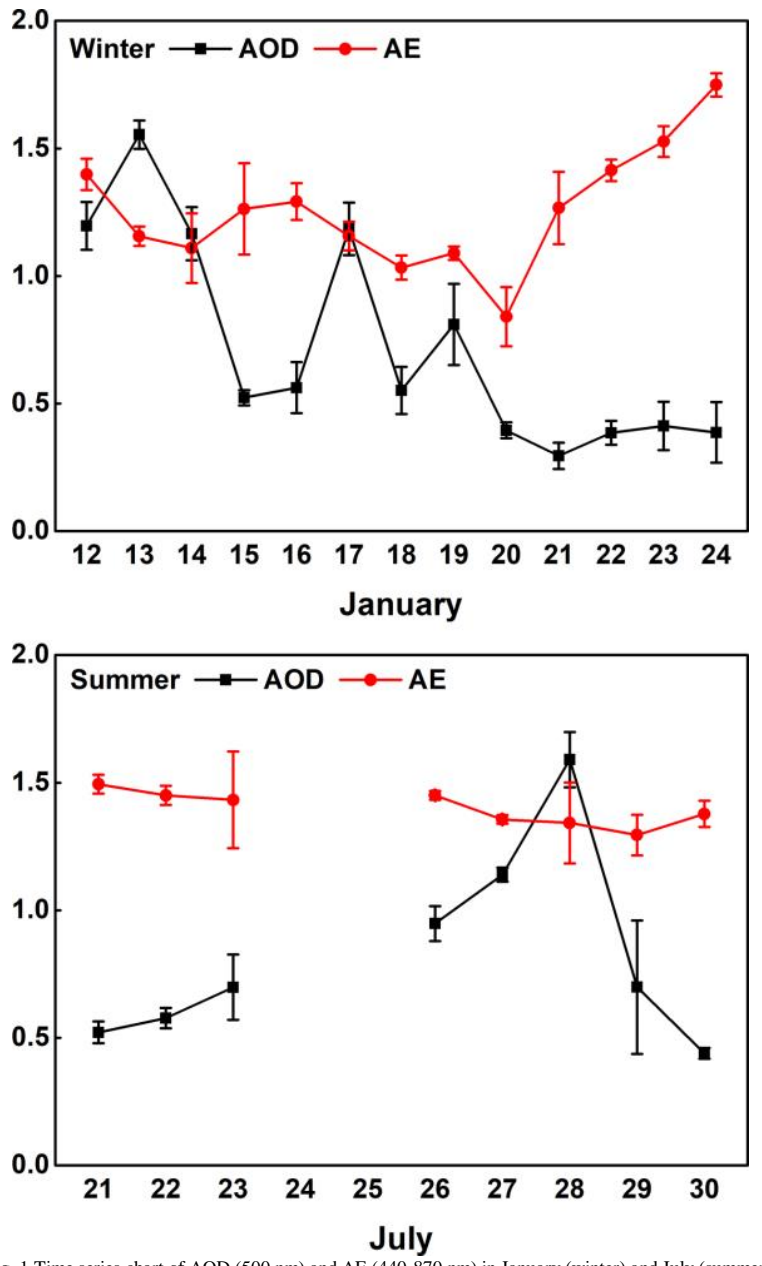

3.1.2 Aerosol size distribution: The ASD is depicted in Fig. 2 , showing a bimodal size distribution dependent on integrative action of fine and coarse mode particles during the clear air and haze periods. The peak of fine mode particle changed from $0.034 \mu \mathrm{m}^{3} / \mu \mathrm{m}^{2}$ to $0.068 \mu \mathrm{m}^{3} / \mu \mathrm{m}^{2}$ in winter and it varied from $0.106 \mu \mathrm{m}^{3} / \mu \mathrm{m}^{2}$ to $0.168 \mu \mathrm{m}^{3} / \mu \mathrm{m}^{2}$ in summer, when haze developed. Meanwhile, the peak of coarse mode particle had no significant changes from clear air to haze periods, and it was around $0.051 \mu \mathrm{m}^{3} / \mu \mathrm{m}^{2}$ in winter and around $0.042 \mu \mathrm{m}^{3} / \mu \mathrm{m}^{2}$ in summer. The fine mode particle increased obviously with haze occurring and it was constantly dominant in summer. While, in winter, the coarse mode particles were preponderance during clear air periods. The particle effective radius increased as well with haze developing, from $0.128 \mu \mathrm{m}$ to $0.166 \mu \mathrm{m}$ in winter and from $0.179 \mu \mathrm{m}$ to $0.229 \mu \mathrm{m}$ in summer. Fig. 3 showed relationships between fine mode particle effective radius and 
relative humidity. The mean relative humidity was $50.8 \%$ and $76.9 \%$ in winter and summer respectively. And the radius increased with increase of the relative humidity, due to the hygroscopic growth in a relatively high humid environment.
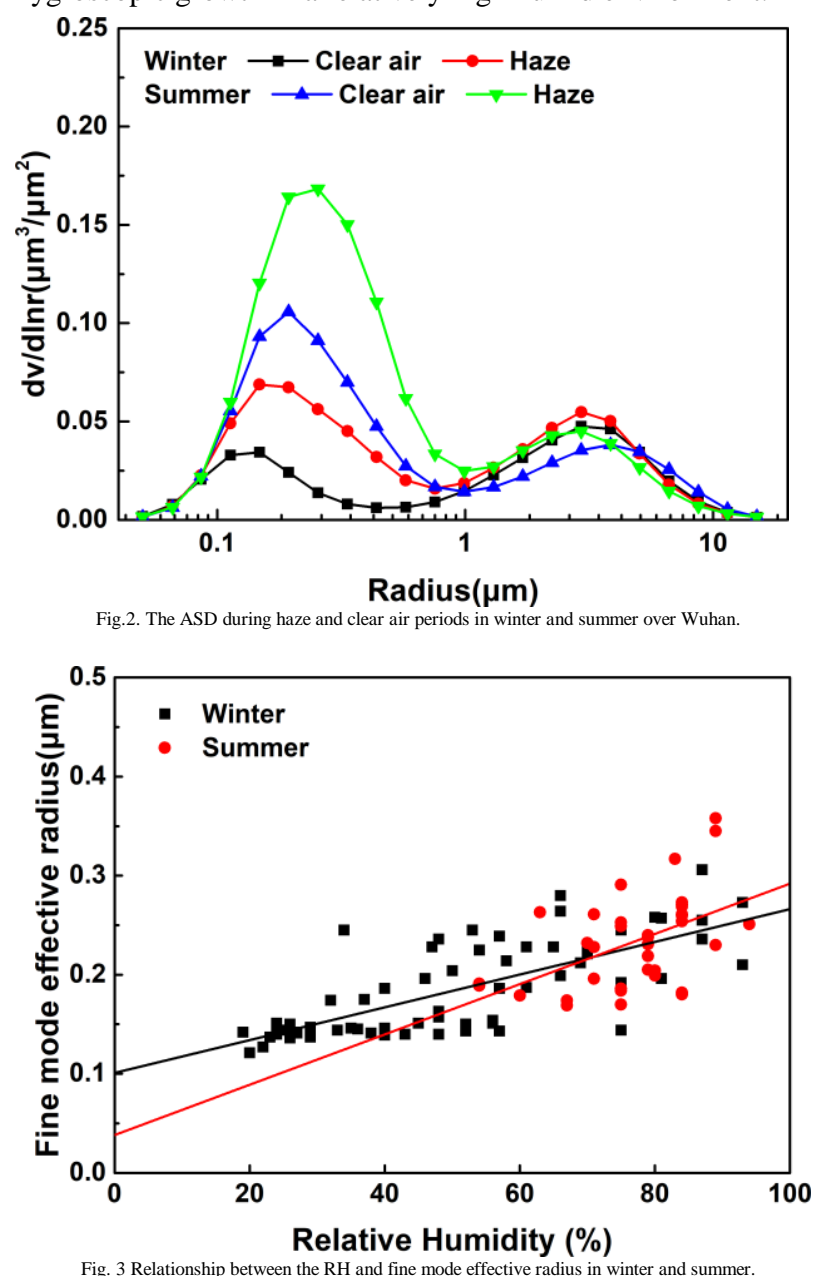

3.1.3 Single scattering albedo: The SSA at four different wavelengths was shown in Fig. 4. The value of SSA increased from $440 \mathrm{~nm}$ to $870 \mathrm{~nm}$ and then decreased at $1020 \mathrm{~nm}$ in winter, indicating the influence of raising large dust particles covered with iron components, which had strong absorption of solar radiation at the UV interval (Sokolik and Toon, 1999).

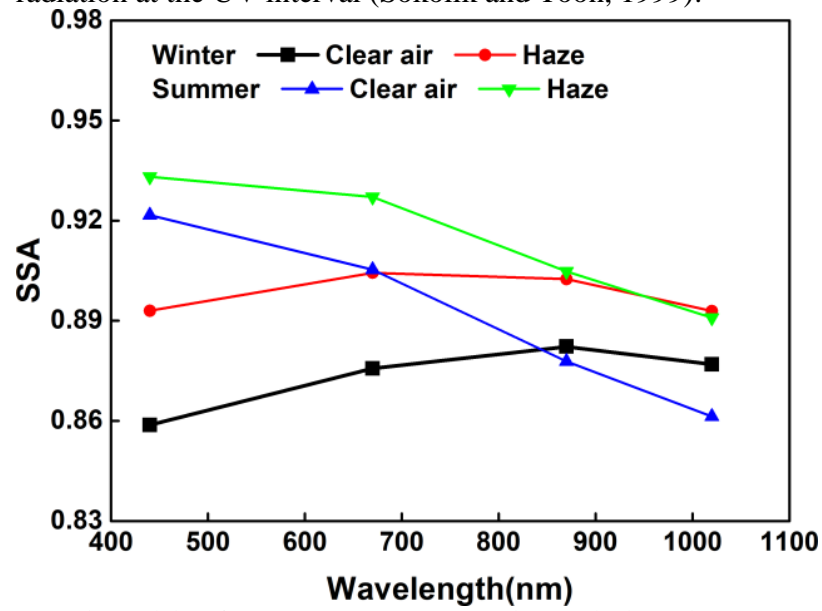

In summer, by contrast, the SSA maintained a decreasing trend and the differences in SSA between clear air and haze condition deceased from $440 \mathrm{~nm}$ to $670 \mathrm{~nm}$. It was due to carbonaceous aerosols from surrounding biomass combustion regions which also show strong absorption capacity and a strong wavelength dependence (Kirchstetter, 2004). In addition, the values of SSA under haze in both the seasons were even higher, indicating that the appearance of numerous non-absorbent aerosols, such as sulfate (Charlson and Hofmann, 1992).

\subsection{Aerosol radiative effects at UV, VIS, NIR, and SW}

3.2.1 Time series of ARE in each sub-band: The variation of earth surface ARE at UV, VIS, NIR, and SW was shown in Fig. 5. The average ARE at UV, VIS, NIR, and SW changed from $-8.29 \mathrm{~W} / \mathrm{m}^{2}$ to $-10.88 \mathrm{~W} / \mathrm{m}^{2}$, from $-43.26 \mathrm{~W} / \mathrm{m}^{2}$ to -66.04 $\mathrm{W} / \mathrm{m}^{2}$, from $-21.90 \mathrm{~W} / \mathrm{m}^{2}$ to $-44.57 \mathrm{~W} / \mathrm{m}^{2}$, and from -73.46 $\mathrm{W} / \mathrm{m}^{2}$ to $-119.49 \mathrm{~W} / \mathrm{m}^{2}$ respectively in winter. And it changed in summer from $-8.32 \mathrm{~W} / \mathrm{m}^{2}$ to $-11.06 \mathrm{~W} / \mathrm{m}^{2}$, from $-56.33 \mathrm{~W} / \mathrm{m}^{2}$ to $-76.94 \mathrm{~W} / \mathrm{m}^{2}$, from $-31.36 \mathrm{~W} / \mathrm{m}^{2}$ to $-48.67 \mathrm{~W} / \mathrm{m}^{2}$, and from $96.01 \mathrm{~W} / \mathrm{m}^{2}$ to $-135.67 \mathrm{~W} / \mathrm{m}^{2}$ respectively.
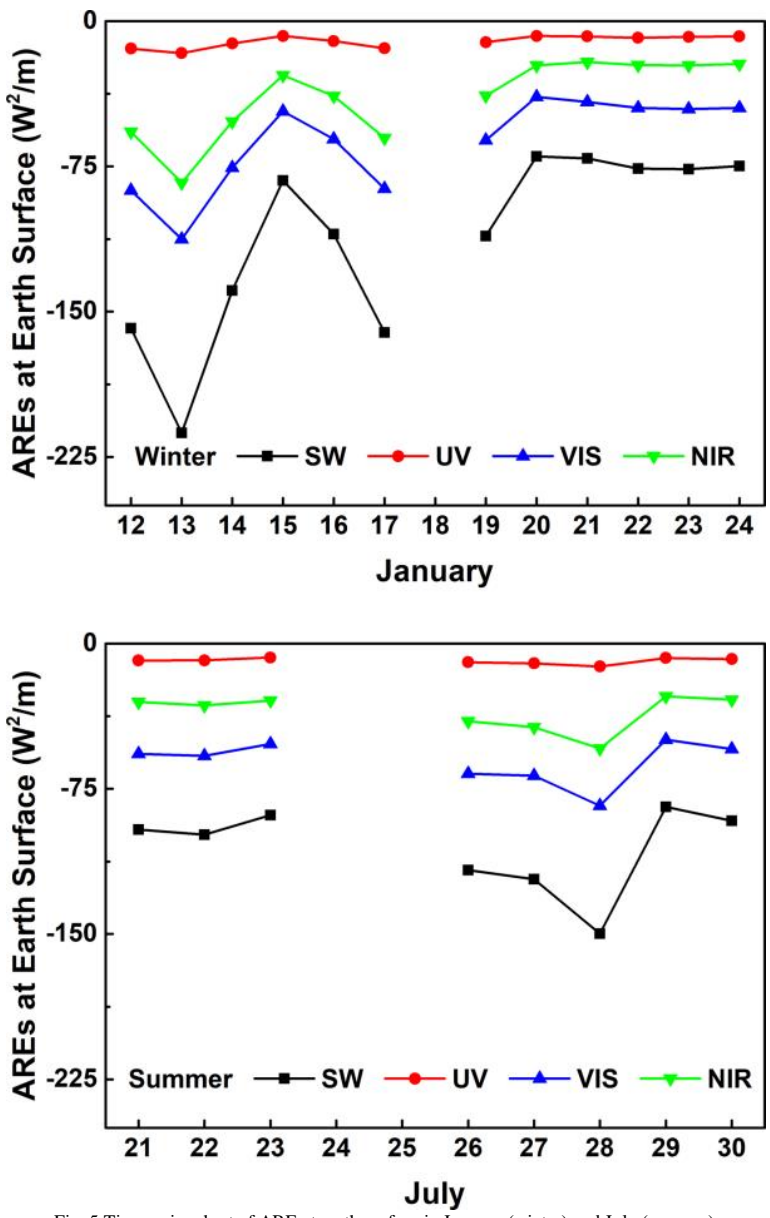

3.2.2 Variation in ARE fraction of each sub-band: In both two seasons, the ARE enhanced with haze occurring. The changes in ARE fraction of UV, VIS, and NIR was displayed in Table. 2. The ARE percentage of UV and VIS in SW decreased, while NIR fraction increased, when the air condition changed from clear to haze. In addition, the Variations in ARE percentage of each sub-band were larger in winter than that in summer.

\begin{tabular}{ccccc} 
& \multicolumn{2}{c}{ Table. 2 ARE fraction of UV, VIS, and NIR in SW } \\
\hline & Winter & \multicolumn{2}{c}{ Summer } \\
& Clear air & Haze & Clear & Haze \\
\hline UV (\%) & 11.3 & 9.5 & 8.7 & 8.2
\end{tabular}




\begin{tabular}{rrrrr} 
VIS $(\%)$ & 58.9 & 55.9 & 58.7 & 56.0 \\
NIR $(\%)$ & 29.8 & 34.6 & 32.6 & 35.8 \\
\hline
\end{tabular}
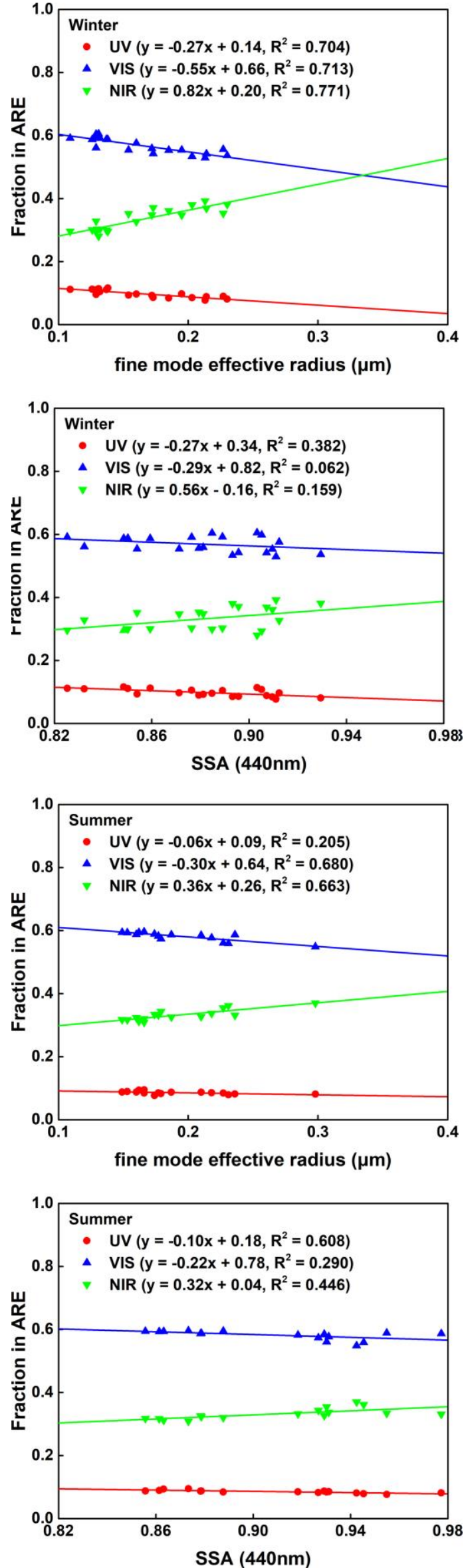

Fig. 6 ARE Fraction variation of UV VIS and NIR in SW with single scattering albedo and fine mode effective radius at SUR. 
In order to further investigate the reason of variations in ARE percentage of each sub-band, Fig. 6 showed the ARE percent variation of UV VIS and NIR in SW with single scattering albedo and fine mode effective radius at earth surface. In winter, the fraction of UV and VIS decreased and NIR fraction increased with the fine mode effective radius increasing. The relationship between ARE Fraction and fine mode effective radius had relatively higher correlation coefficient (R2) of 0.704 in UV, 0.713 in VIS, and 0.771 in NIR, compared with the relationship of SSA. In summer, by contrast, the ARE Fraction of VIS and NIR had high R2 (0.680 and 0.663) with effective radius, while the ARE Fraction of UV depended much more on SSA with R2 of 0.608 . It may be owing to the increase in carbonaceous aerosols under haze conditions. According to the Mie theory (Mie, 1908), the increase of particle radius due to hygroscopic growth under high humidity conditions enhanced forward scattering and decreased backward scattering. And because of wavelength dependence, this effect had more sensitive to short wavelength solar light. Thus, in general, with the increased of particle radius, the ARE fraction of UV and VIS decreased and it of NIR increased in SW.

\subsection{Trajectory analysis with active fire points}

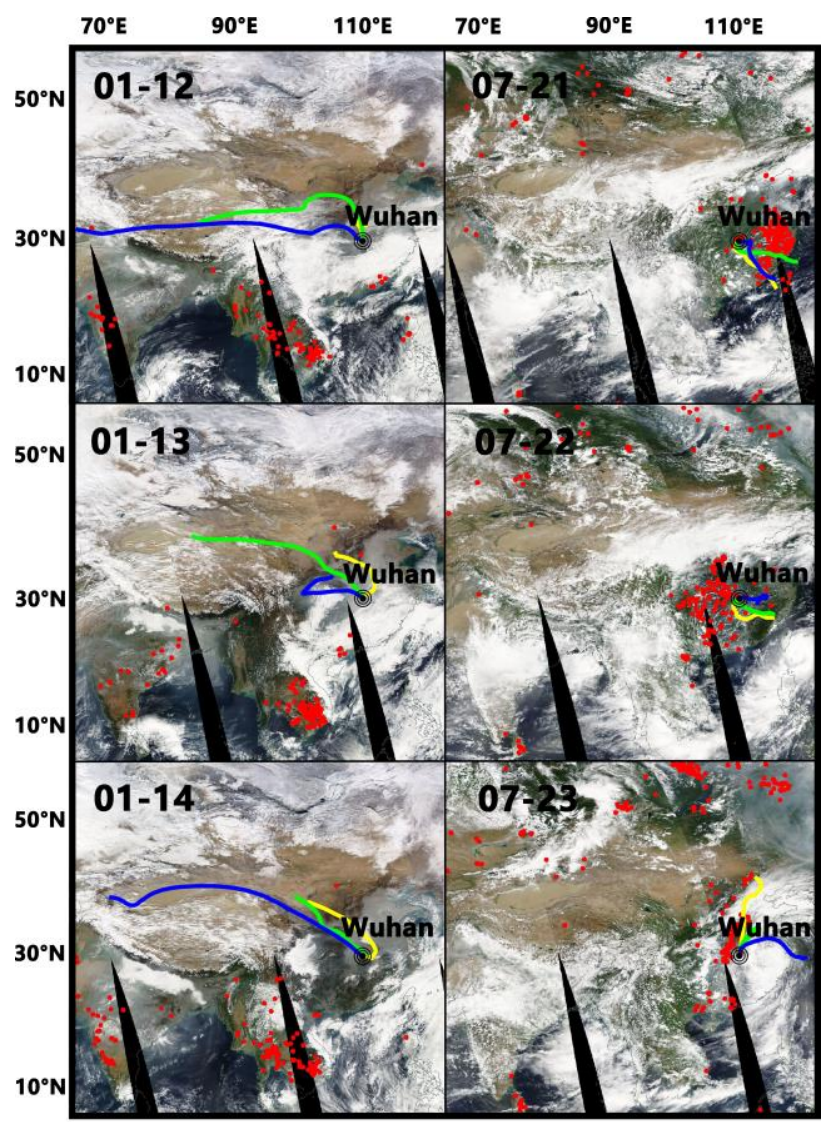

Fire Points from MODIS •

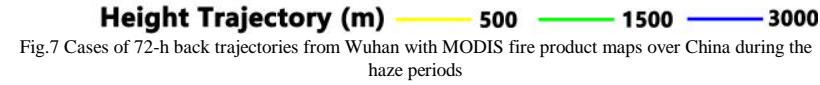

Cases of 72-h back trajectories at $500 \mathrm{~m}, 1500 \mathrm{~m}$, and $3000 \mathrm{~m}$ simulated by the HYSPLIT were shown in fig. 7 and it built connections between local and regional pollution. January 1214 and July 21-23 were typical cases that were analyzed surrounding the combustion influence on Wuhan. Long-range trajectories appeared in January from Northwest China, where was almost no fires were observed, while from the areas where fire was observed by MODIS measurements occurred around Southern and Southwest Wuhan. It showed that air-masses arrived at Wuhan without the influence of other areas where fire was observed. Short-range trajectories, by contrast, appeared in July from southwest and northwest of Wuhan. It was obvious that air brought pollutants produced by biomass combustion from regions with active fires and accumulated over Wuhan.

\section{CONCLUSIONS}

In this study, aerosol optical properties from sun-sky radiometer and their AREs in ultraviolet (UV), visible (VIS), near-infrared (NIR), and shortwave (SW) from libRadtran model were investigated completely during haze periods in summer and winter of Wuhan. An increase of mean AOD $(500 \mathrm{~nm})$ was from 0.34 to 0.79 in winter and from 0.64 to 1.36 in summer, when haze occurring. The peak value of fine mode particles in winter increased from $0.034 \mu \mathrm{m}^{3} / \mu \mathrm{m}^{2}$ to $0.068 \mu \mathrm{m}^{3} / \mu \mathrm{m}^{2}$. In summer, fine mode particles had always been dominant, and showed a rapid increase for the peak value from $0.105 \mu \mathrm{m}^{3} / \mu \mathrm{m}^{2}$ to 0.168 $\mu \mathrm{m}^{3} / \mu \mathrm{m}^{2}$. The value of SSA showed a similar trend in both the seasons where it was much higher during haze periods, indicating an increase of non-absorbent particles, although the absorbent particles also increased. In addition, the value of the SSA in winter increased from $440 \mathrm{~nm}$ to $670 \mathrm{~nm}$ and then decreased at $1020 \mathrm{~nm}$, indicating the strong absorption of solar radiation at a short wavelength.

The ARE at UV, VIS, NIR, and SW changed in winter (summer) from $-8.29 \mathrm{~W} / \mathrm{m}^{2}$ to $-10.88 \mathrm{~W} / \mathrm{m}^{2}\left(-8.32 \mathrm{~W} / \mathrm{m}^{2}\right.$ to $\left.-11.06 \mathrm{~W} / \mathrm{m}^{2}\right)$, from $-43.26 \mathrm{~W} / \mathrm{m}^{2}$ to $-66.04 \mathrm{~W} / \mathrm{m}^{2}\left(56.33 \mathrm{~W} / \mathrm{m}^{2}\right.$ to -76.94 $\left.\mathrm{W} / \mathrm{m}^{2}\right)$, from $-21.90 \mathrm{~W} / \mathrm{m}^{2}$ to $-44.57 \mathrm{~W} / \mathrm{m}^{2}\left(-31.36 \mathrm{~W} / \mathrm{m}^{2}\right.$ to $\left.48.67 \mathrm{~W} / \mathrm{m}^{2}\right)$, and from $-73.46 \mathrm{~W} / \mathrm{m}^{2}$ to $-119.49 \mathrm{~W} / \mathrm{m}^{2}(-8.32$ $\mathrm{W} / \mathrm{m}^{2}$ to $-11.06 \mathrm{~W} / \mathrm{m}^{2}$ ) respectively, when air conditions changed from clear to hazy. The ARE fraction of UV, VIS in SW decreased while the ARE fraction of NIR increased during haze periods. According to the Mie theory, the increase of particles size due to hygroscopic growth under high humidity conditions enhanced forward scattering and decreased backward scattering. And it had more sensitive to short wavelength light because of wavelength dependence.

The influence of the surrounding regions where fire was observed was analyzed using the HYSPLIT model to verify the contribution of surrounding biomass combustion to haze in Wuhan. In summer, air-masses passed through areas in the North and brought pollutants to Wuhan. While, in winter, pollutants were carried from Southeast Asia and India. It had almost no influence on the areas surrounding Wuhan.

A detailed investigation of the aerosol optical and associated radiative properties in two seasons with different climatic conditions and pollutant sources enhanced the understanding and assessment of haze variation mechanisms and were also useful in more accurately assessing the radiative effect of aerosols on localized climate.

\section{ACKNOWLEDGEMENTS (OPTIONAL)}

This work was supported by the National Key R\&D Program of China (Grant No.2018YFB0504500), the National Natural Science Foundation of China (Grant No. 41875038 and No. 41801261), the Natural Science Foundation of Hubei Province (Grant No. 2017CFB404), the Wuhan University Luojia Talented Young Scholar Project. We are grateful to the National 
Climatic Data Center (NCDC) for humidity parameters used in this study.

\section{REFERENCES}

Albrecht, B. A. (1989), AEROSOLS, CLOUD MICROPHYSICS, AND FRACTIONAL CLOUDINESS, Science, 245(4923), 1227-1230, doi:10.1126/science.245.4923.1227.

Ångström, A. (1929), On the Atmospheric Transmission of Sun Radiation and on Dust in the Air, Geografiska Annaler, 11(40), 156-166.

Charlson, R. J., and D. J. Hofmann (1992), Climate forcing by anthropogenic aerosols, Science, 255(5043), 423-430.

Che, H., X. Zhang, H. Chen, B. Damiri, P. Goloub, Z. Li, X. Zhang, Y. Wei, H. Zhou, and F. Dong (2009), Instrument calibration and aerosol optical depth validation of the China Aerosol Remote Sensing Network, Journal of Geophysical Research Atmospheres, 114(D3), D03206.

Draxier, R. R., and G. D. Hess (1998), An overview of the HYSPLIT_4 modelling system for trajectories, dispersion and deposition, Aust. Meteorol. Mag., 47(4), 295-308.

Dubovik, O., B. Holben, T. F. Eck, A. Smirnov, Y. J. Kaufman, M. D. King, D. Tanre, and I. Slutsker (2002), Variability of absorption and optical properties of key aerosol types observed in worldwide locations, Journal of the Atmospheric Sciences, 59(3), 590-608, doi:10.1175/1520 0469(2002)059<0590:voaaop>2.0.co;2.

Dubovik, O., and M. D. King (2000), A flexible inversion algorithm for retrieval of aerosol optical properties from Sun and sky radiance measurements, J. Geophys. Res.-Atmos., 105(D16), 20673-20696, doi:10.1029/2000jd900282.

Dubovik, O., A. Smirnov, B. N. Holben, M. D. King, Y. J. Kaufman, T. F. Eck, and I. Slutsker (2000), Accuracy assessments of aerosol optical properties retrieved from Aerosol Robotic Network (AERONET) Sun and sky radiance measurements, Journal of Geophysical Research: Atmospheres, 105(D8), 9791-9806, doi:10.1029/2000jd900040.

Eck, T. F., B. N. Holben, J. S. Reid, O. Dubovik, A. Smirnov, N. T. O'Neill, I. Slutsker, and S. Kinne (1999), Wavelength dependence of the optical depth of biomass burning, urban, and desert dust aerosols, Journal of Geophysical Research: Atmospheres, 104(D24), 31333-31349, doi:10.1029/1999jd900923.

Guo, S., et al. (2014), Elucidating severe urban haze formation in China, Proc. Natl. Acad. Sci. U. S. A., 111(49), 17373-17378, doi:10.1073/pnas.1419604111.

Hansen, J., M. Sato, and R. Ruedy (1997), Radiative forcing and climate response, Journal of Geophysical Research, 102(D6), 6831-6864.

Haywood, J., and O. Boucher (2000), Estimates of the direct and indirect radiative forcing due to tropospheric aerosols: A review, Reviews of Geophysics, 38(4), 513-543.

Holben, B. N., et al. (1998), AERONET - A federated instrument network and data archive for aerosol characterization, Remote Sensing of Environment, 66(1), 1-16, doi:10.1016/s0034-4257(98)00031-5.

Huang, R. J., Y. Zhang, C. Bozzetti, K. F. Ho, J. J. Cao, Y. Han, K. R. Daellenbach, J. G. Slowik, S. M. Platt, and F. Canonaco (2014), High secondary aerosol contribution to particulate pollution during haze events in China, Nature, 514(7521), 218.

Kirchstetter, T. W. (2004), Evidence that the spectral dependence of light absorption by aerosols is affected by organic carbon, Journal of Geophysical Research Atmospheres, 109(D21), -.

Lyu, X. P., N. Chen, H. Guo, L. W. Zeng, W. H. Zhang, F. Shen, J. H. Quan, and N. Wang (2016), Chemical characteristics and causes of airborne particulate pollution in warm seasons in Wuhan, central China, Atmos. Chem. Phys., 16(16), 10671-10687, doi:10.5194/acp-16-10671-2016.

Lyu, X. P., Z. W. Wang, H. R. Cheng, F. Zhang, G. Zhang, X. M. Wang, Z. H. Ling, and N. Wang (2015), Chemical characteristics of submicron particulates (PM1.0) in Wuhan, Central China, Atmospheric Research, 161, 169-178, doi:10.1016/j.atmosres.2015.04.009.

Mayer, B., and A. Kylling (2005), Technical note: The libRadtran software package for radiative transfer calculations - description and examples of use, Atmospheric Chemistry \& Physics, 5(2005), 18551877.

Mie, G. (1908), Beitrage Zur Optik Truber Medien, Speziell Kolloidaler Metallosungen, Annalen Der Physik, 25(3), 377

Moody, E. G., M. D. King, S. Platnick, C. B. Schaaf, and F. Gao (2005), Spatially complete global spectral surface albedos: value-added datasets derived from Terra MODIS land products, IEEE Transactions on Geoscience \& Remote Sensing, 43(1), 144-158.

Ramanathan, V., P. J. Crutzen, J. T. Kiehl, and D. Rosenfeld (2001), Atmosphere - Aerosols, climate, and the hydrological cycle, Science, 294(5549), 2119-2124, doi:10.1126/science.1064034.

Sokolik, I. N., and O. B. Toon (1999), Incorporation of mineralogic composition into models of the radiative properties of mineral aerosol from UV to IR wavelengths, Journal of Geophysical Research Atmospheres, 104(D8), 9423-9444.

Stein, A. F., R. R. Draxler, G. D. Rolph, B. J. B. Stunder, M. D. Cohen, and F. Ngan (2015), NOAA'S HYSPLIT ATMOSPHERIC TRANSPORT AND DISPERSION MODELING SYSTEM, Bull. Amer. Meteorol. Soc., 96(12), 2059-2077, doi:10.1175/bams-d-14-00110.1.

Stocker, T. F., D. Qin, G. K. Plattner, M. Tignor, S. K. Allen, J. Boschung, A. Nauels, Y. Xia, B. Bex, and B. M. Midgley (2013), IPCC, 2013: Climate Change 2013: The Physical Science Basis. Contribution of Working Group I to the Fifth Assessment Report of the Intergovernmental Panel on Climate Change, Computational Geometry, 18(2), 95-123.

Tao, M., L. Chen, Z. Wang, J. Wang, J. Tao, and X. Wang (2016), Did the widespread haze pollution over China increase during the last decade? A satellite view from space, Environmental Research Letters, 11(5), 054019.

Yaoqing, T., Y. I. N. Yan, Q. Ling, and A. N. Junlin (2007), Analysis of the characteristics of hazy phenomena in Nanjing area, China Environmental Science, 27(5), 584-588.

Yele Sun, \$, Guoshun Zhuang, $\dagger, \$$, Aohan Tang, Wang, \$Ying, and Z. An§ (2006), Chemical Characteristics of PM2.5 and PM10 in Haze-Fog Episodes in Beijing, Environmental Science \& Technology, 40(10), 3148.

Zhang, M., Y. Ma, W. Gong, and Z. Zhu (2014), Aerosol Optical Properties of a Haze Episode in Wuhan Based 
The International Archives of the Photogrammetry, Remote Sensing and Spatial Information Sciences, Volume XLII-3/W5, 2018 ISPRS Workshop on Remote Sensing and Synergic Analysis on Atmospheric Environment, 7-8 November 2018, Guangzhou, China

on Ground-Based and Satellite Observations, Atmosphere, 5(4), 699-719. 